\title{
Increased Fat Mass Leads To Bone Loss, A Prospective Short-Term, 18-Week Study In Young Healthy Men Undergoing Basic Training of The Swiss Army
}

\author{
Michael Straessle \\ University of Zurich \\ Jonas Grossmann \\ University of Zurich / ETH Zurich \\ Patrick Eppenberger \\ University of Zurich \\ Alexander Faas \\ Swiss Armed Forces, Switzerland \\ Yvanka Jerkovic \\ Swiss Armed Forces, Switzerland \\ Joël Floris \\ University of Zurich \\ Lena Öhrström \\ University of Zurich \\ Gülfirde Akgül \\ University of Zurich \\ Lafi Aldakak \\ University of Zurich
}

Frank J. Rühli

University of Zurich

Nicole Bender

University of Zurich

Kaspar Staub ( $\sim$ kaspar.staub@iem.uzh.ch )

University of Zurich

\section{Research Article}

Keywords: ultrasound, bone, physical, training

Posted Date: December 27th, 2021 
DOI: https://doi.org/10.21203/rs.3.rs-1077246/v1

License: (a) (i) This work is licensed under a Creative Commons Attribution 4.0 International License. Read Full License 


\section{Abstract}

Background: Quantitative ultrasound (QUS) methods have been widely used to assess bone status in osteoporosis. For follow-up examinations, there are no recommendations regarding the use of QUS due to a lack of data. This study aimed to investigate the longitudinal use of QUS in 4 months of military training to assess bone remodelling in association with physical activity and anthropometry.

Subjects and methods: We analysed the changes in bone health using calcaneal quantitative ultrasound (Sonost-3000) as well as the impact of anthropometry, body composition, and physical activity in young men at the start $(n=104)$ and 18 weeks later after basic training $(n=73)$.

Results: After basic training, the subjects were heavier, slightly taller, and had higher fat mass and grip strength. An overall decrease in physical activity and bone ultrasound attenuation (BUA) was observed. A negative correlation between the development of fat mass and physical activity with BUA was found, with fat mass as the highest impact factor. Development of grip strength correlated positively with SOS, while skeletal muscle mass and waist circumference correlated negatively. Development of skeletal muscle mass and weight had the highest impact on SOS.

Conclusion: Overall, subjects were heavier, taller, and fatter and showed increased grip strength, decreased physical activity, and loss of bone health. It is alarming that the increase in fat mass already has a negative effect on the bone structure after 18 weeks. As seen in other studies, the impact of force on bone during walking is insufficient to strengthen it. The results imply that the selected troops of the Swiss army recruits (air defence) have too little high-impact physical activity during their basic training, what should be changed in the future. To verify the worrying results from our study, a prospective randomized study with a survey of low and high impact activities as well as a detailed survey of eating and nutritional habits during basic training should be carried out. QUS seems to be a good tool for assessing bone status, even in the event of short-term changes.

\section{Introduction}

Quantitative ultrasound (QUS) methods have been widely used to assess bone status in osteoporosis. Osteoporosis is a major public health problem, with a prevalence of $16 \%$ in men and $30 \%$ in women in the USA in 2017 (1). In the EU, 3.5 million cases of fragility fractures (defined as a fall from standing height or less, resulting in a fracture) were caused by osteoporosis, costing an estimated 2,050 million CHF per year in Switzerland in 2010 (2). The WHO defined osteoporosis in 1994 as a systemic bone disease with loss of bone strength and a higher risk for fracture. Dual-energy X-ray absorptiometry (DXA) measures bone mineral density (BMD) and is known to have the greatest clinical utility for bone status assessment to evaluate the risk for fracture. Osteoporosis is defined as a BMD lower than 2.5 standard deviations (SD) compared to the bone density in the population at 30 years (3).

QUS is a convenient and popular screening tool for osteoporosis. QUS can predict osteoporotic fractures (4-9) and differentiate between subjects with and without fragility fractures $(10,11)$. Systematic reviews 
and meta-analyses, as well as the International Society for Clinical Densitometry (ISCD), validated QUS as being a good predictor for hip and other non-vertebral fractures and as reliable as DXA (12-14). QUS is an independent predictor of fracture in men and women, even after adjusting for DXA (15), and showed the same area under the curve as DXA in calculating the risk for fracture $(9,16)$. Direct correlations between QUS and DXA showed a sensitivity of $70-85 \%$ and a specificity of $44-70 \%$ for detecting osteoporosis $(33,34)$. The US Preventive Services Task Force states that QUS at the calcaneus predicts fractures of the femoral neck, hip, and spine as effectively as DXA (17). However, despite the comparable effectiveness of the two modalities, the ISCD asserts that differences between heel QUS and central DXA can occur and do not imply methodological errors (14). Sources of discordance can include varying skeletal site measurements or ultrasound wave physics and X-rays. Both are highly sensitive to the quantity of bone but have varying interactions (18). Central DXA measurements at the spine and femur are preferred for therapeutic indications; however, if it cannot be performed, calcaneus QUS using devicespecific thresholds may be indicated for therapy (19).

Current clinical calcaneal bone ultrasound devices measure two parameters after passing the bone: broadband ultrasound attenuation (BUA) and speed of sound (SOS). SOS and BUA provide information on the mechanical and structural properties of bone, which are distinct from $\operatorname{BMD}(20,21)$. SOS is influenced mostly by structural properties, such as the density and architecture of trabeculae, and as well as by the mechanical properties of bone, such as elasticity and compressive strength (22). BUA results from a combination of absorption and scattering and reflects structural properties such as bone size, bone volume, and orientation of the trabecular network. This method is particularly like the measurement of BMD using DXA $(23,24)$.

Most studies investigating bone status are performed in the elderly, particularly postmenopausal women, concerning osteoporosis. Studies in younger men are rare, but the extrinsic effects on bone status can be analysed with the same power. In young adults, physical activity influences DXA and QUS. High-impact sports (e.g. rugby and powerlifting) lead to higher BMD than low-impact sports (such as rowing, cycling, and swimming) (25). Such associations have also been observed in military settings. In young healthy recruits, a high response of bone density and microarchitecture was observed after 8-10-week physical training. During a 3-month circuit training, an increase in SOS and BUA in young female students was observed (26). The same observation of increasing SOS and BUA was made after 6 months of military service, while physical training had the highest impact factor (27). An investigation of a 12-week program of physical training showed an increase in BMD, BUA, and bone volume (particularly in cortical and periosteal volume), but no change in SOS (28). An 18-month follow-up study (with 3-monthly QUS measurements) showed a continuous increase in BUA in gymnasts compared to controls, but with no change in SOS (29).

As mentioned previously, the quality of QUS measurements has been validated for predicting the risk of fracture in family practice. For follow-up examinations, there are no recommendations regarding the use of QUS due to a lack of data. This study aimed to investigate the longitudinal use of QUS in 4 months of military training to assess bone remodelling in association with physical activity and anthropometry. 
Therefore, we aimed to answer the following research questions. Is there a change in bone status measurable by QUS after a short-term period in a sample of healthy young men? Is there an association between physical activity and/or anthropometric measurements?

\section{Methods}

The first measurement took place in March 2017 in Kloten (Canton Zurich, Switzerland); the follow-up measurement occurred 18 weeks later in July 2017 in Neunkirch (Canton Schaffhausen, Switzerland). The precise study protocol has been described previously $(30,31)$. The subjects were Swiss male recruits from the air defence of the Swiss Armed Forces aged 19-23 years, starting their basic military training for 18 weeks. No selection was made for socioeconomic background, regional origin, or demographic factors. One hundred and four young men participated at the beginning; 73 (70.2\%) were reassessed 4 months later. Due to splitting and relocation of subjects from the initial troop or quitting the service, we were not able to re-assess 31 subjects; thus, they were excluded from the study. The same measurement protocol and devices were used during both examinations where participation was voluntary. Written and oral briefings were provided at the start of the study and shortly before the examination, respectively. The participants signed a detailed informed consent form. This study was approved by the Ethics Committee of the Canton of Zurich (No. 2016-01625).

\section{Calcaneal quantitative ultrasound}

We used a calcaneal site QUS device (Sonost-3000, medical ECONET, Oberhausen, Germany) which measured the velocity of sound waves as the speed of sound ( $\mathrm{SOS}$ in $\mathrm{m} / \mathrm{s}$ ) and the attenuation after passing the bone as bone ultrasound attenuation (BUA in $\mathrm{dB} / \mathrm{MHz}$ ). In the range of the ultrasound measurements (between 0.3 and $0.65 \mathrm{MHz}$ ), theoretical calculations illustrated a linear function of attenuation dependent on frequency, and a linear positive correlation between BUA and density (32). This observation was also observed in experimental studies $(18,33,34)$. In addition, QUS devices calculate the bone quality index (BQI) (e.g. stiffness index and estimated BMD) from SOS and BUA using the manufacturer's equation. Because of the manufacturer's different calculations, there is no comparability between the different devices. Therefore, we excluded the BQI for further investigations.

\section{Body composition analysis and anthropometric measurements}

For the bioelectrical impedance analysis (BIA), we used a medical 8-point body composition analyser (Seca mBCA 515, Reinach, Switzerland). We measured body fat mass (\%), visceral fat mass (I), skeletal muscle mass $(\mathrm{kg})$, body weight $(\mathrm{kg})$, and total energy expenditure (kcal/day). Participants stood barefoot on footpads (each side with two electrodes) and held their hands on handpads (each side with two electrodes). Compared to the four-compartment measurements as the gold standard for determining body composition, the Seca body composition analyser correlates with $98 \%$, which suggests an equivalent quality (35). During the BIA measurements, we performed manual measurements of the waist circumference according to the WHO protocol; we used a handheld tape (Seca 201, Reinach, Switzerland) with stretch resistant quality and automatic retraction, at the midpoint between the lowest point of the 
ribcage and the highest point of the pelvis bone, while the participant stood in a relaxed upright position and breathing normally (36). A standard stadiometer was used to determine the height (Seca 274, Reinach, Switzerland), standing barefoot in a straight-up position, with the feet together. Body mass index $\left(\mathrm{kg} / \mathrm{m}^{2}\right)$ was calculated from height and weight. BMI values were classified as underweight $(<18.5$ $\left.\mathrm{kg} / \mathrm{m}^{2}\right)$, normal weight $\left(18.5-24.9 \mathrm{~kg} / \mathrm{m}^{2}\right)$ and overweight $\left(>25.0 \mathrm{~kg} / \mathrm{m}^{2}\right)$, according to WHO guidelines. Grip strength was measured using a hand dynamometer.

\section{Physical activity assessment}

The Global Physical Activity Questionnaire (GPAQ) was used to evaluate physical activity at the beginning of the study (to assess physical activity before starting the basic training) and at follow-up (to assess physical activity during the basic training) (37). The questionnaire contained items about low-, mid-, and high-intensity activities during work (e.g. for low-intensity: businessman, merchandiser; for midintensity: housekeeper, gardener, farmer; for high-intensity: lumberjack, construction worker, bricklayer, roofer, fitness instructor) and leisure (e.g. for low-intensity: sedentary activities, fishing; for mid-intensity: casual cycling/swimming, dancing, riding, yoga, strength training, climbing; for high-intensity: soccer, football, athletics, aerobic, ballet, jogging, boxing, intense cycling/swimming). The GPAQ calculates the metabolic equivalents (MET) per week, which are commonly used to express the intensity of physical activities. MET is the resting metabolic rate and defined as the energy consumption of sitting quietly. One MET is equivalent to a caloric consumption of $1 \mathrm{kcal} / \mathrm{kg} /$ hour. During moderate activity, the caloric consumption is four times as high as the resting metabolic rate and during vigorous activity eight times as high. To calculate the physical activity as overall energy expenditure, the sum of MET of moderate activities (MET multiplied by 4), and of MET of vigorous activities (MET multiplied by 8), was used.

\section{Sports and smoker groups}

The subjects were asked about their smoking and sports habits. The subjects were divided into groups as athletes and non-athletes (regular sportive activities in leisure time vs. no sportive activities in leisure time), smokers and non-smokers (number of cigarettes per day $>0$ vs. number of cigarettes per day $=0$ ).

\section{Statistics}

BUA, SOS, body composition, anthropometrics, and physical activity were reported as mean values \pm standard deviation (SD) for overall and for athletes, non-athletes, smoker, and non-smoker groups. Changes in variables (=delta) were defined as values at follow-up minus values at the beginning. The normal distribution of each parameter was visually assessed using histograms.

Changes in the averages between the beginning and end of the study were tested using a two-tailed oneway t-test. We assessed physical activity before and during basic training and subsequently investigated its influence on the changes in SOS and BUA. Correlations were calculated using Pearson's correlation coefficient. Using stepwise backward methods, we developed multiple linear models for changes in SOS and BUA, including anthropometrics, body composition, physical activity, and smoking status. 
All methods were carried out in accordance with relevant guidelines and regulations.

\section{Results}

The demographic and lifestyle factors of the participants are shown in Table 1. At baseline, the age of the participants ranged from 18.8 to 23.9 years (mean 20.5, SD 1.0), height ranged from $1.66 \mathrm{~m}$ to $1.94 \mathrm{~m}$ (mean 1.78, SD 0.07), weight ranged from $50.6 \mathrm{~kg}$ to $104.7 \mathrm{~kg}$ (mean 73.2, SD 12.4), and BMI ranged from 16.4 to $30.1 \mathrm{~kg} / \mathrm{m}^{2}$ (mean 23.0, SD 3.3). Eighteen subjects (24.7\%) were overweight (BMI > $25.0)$, and three subjects (4.1\%) were underweight (BMI < 18.5). At follow-up 18 weeks later, 20 of 73 subjects (27.4\%) were overweight, and the same three subjects were still underweight (4.1\%). All variables were distributed symmetrically. There were 43 subjects in the athletes group (58.9\%) and 30 subjects in the non-athletes group (41.1\%). In the smoker group $(n=34,46.6 \%)$, two stopped smoking. In the nonsmoker group, $(n=39,53.4 \%)$, two started smoking during the study.

Most variables (except height) showed regression to the mean-like behaviour with an approximation to the mean, as shown in Appendix Figure 1 A-D. High values at the beginning dropped and low values increased during the basic training. Weight, height, fat mass, and grip strength increased after the basic training. BUA and physical activity decreased during the same period. No changes were observed in BMI, fat-free mass, skeletal muscle mass, waist circumference, and SOS (Table 1). Comparing the athletes and non-athletes groups, as well as the smoker and non-smoker groups, no further findings compared to the total study population were detected (Appendix Tables 1 and 2).

Table 1. Descriptive characteristics of subjects at beginning and follow-up with $p$-values of changes 


\begin{tabular}{|c|c|c|c|c|c|c|}
\hline Characteristics & start & $\pm \mathrm{SD}$ & follow-up & $\pm S D$ & p-Value & \\
\hline Age (years) & 20.5 & \pm 1.0 & & & & \\
\hline \multicolumn{7}{|l|}{ Bone measurements } \\
\hline $\operatorname{SOS}(\mathrm{m} / \mathrm{s})$ & 1545.3 & \pm 15.5 & 1543.5 & \pm 14.6 & 0.145 & \\
\hline $\mathrm{BUA}(\mathrm{dB} / \mathrm{MHz})$ & 87.8 & \pm 16.8 & 81.2 & \pm 16.1 & $<0.001$ & *** \\
\hline \multicolumn{7}{|l|}{ Anthropometrics } \\
\hline Grip strength (kg) & 47.8 & \pm 9.5 & 51.9 & \pm 9.2 & $<0.001$ & $* * *$ \\
\hline BMI $\left(\mathrm{kg} / \mathrm{m}^{2}\right)$ & 23.0 & \pm 3.3 & 23.2 & \pm 3.1 & 0.122 & \\
\hline Fat mass (\%) & 13.7 & \pm 7.1 & 14.6 & \pm 6.9 & 0.003 & ** \\
\hline Fat free mass $(\mathrm{kg})$ & 62.46 & \pm 6.7 & 62.47 & \pm 6.2 & 0.964 & \\
\hline Skeletal muscle mass (kg) & 30.67 & \pm 3.7 & 30.71 & \pm 3.3 & 0.740 & \\
\hline Waist circumference $(\mathrm{m})$ & 0.7999 & \pm 0.1 & 0.8004 & \pm 0.1 & 0.890 & \\
\hline Weight (kg) & 73.2 & \pm 12.4 & 73.9 & \pm 11.6 & 0.041 & $*$ \\
\hline Height (m) & 1.78 & \pm 0.1 & 1.79 & \pm 0.1 & $<0.001$ & $* * *$ \\
\hline Visceral adipose tissue (I) & 0.73 & \pm 0.8 & 0.72 & \pm 0.6 & 0.771 & \\
\hline Physical activity (MET) & 7547.9 & \pm 6570.6 & 3815.3 & \pm 3596 & $<0.001$ & $* * *$ \\
\hline
\end{tabular}

Table 1: Descriptive characteristics of subjects at start and 18 weeks later at follow-up $(n=73)$. Subjects who could not be reassessed in follow-up were excluded from the study $(n=31)$ and are not shown in this table. $S D=$ standard deviation. $p$-value with level of significance $<5 \%$. SOS=speed of sound. BUA=bone ultrasound attenuation. BMI=body mass index. MET=metabolic equivalents per week.

Next, the correlation of bone parameters (SOS and BUA) and independent variables were analysed (Table 2). After basic training, SOS did not significantly change. Regarding correlations between the delta of independent variables and delta SOS (delta = value after basic training minus value at the start), a positive correlation was observed with grip strength; negative correlations were found with skeletal muscle mass and waist circumference (Table 2, Appendix Figure A2). Deltas in weight, height, BMI, and physical activity were not correlated with changes in SOS.

Deltas of fat mass and physical activity were negatively correlated with delta BUA levels. With increasing fat mass or physical activity, a decrease in BUA was observed, and vice versa (Appendix Figure A3). 
Deltas of weight, height, BMI, grip strength, skeletal muscle mass, and waist circumference did not correlate with delta BUA.

Table 2. Correlation values between delta of SOS and BUA and delta of variables

\begin{tabular}{|c|c|c|c|}
\hline Variable (delta) & & sos & BUA \\
\hline \multirow[t]{2}{*}{ Grip strength (kg) } & $r$ & 0.06 & - \\
\hline & $p$ & 0.032 & 0.162 \\
\hline \multirow[t]{2}{*}{ BMI $\left(\mathrm{kg} / \mathrm{m}^{2}\right)$} & $r$ & - & - \\
\hline & $p$ & 0.063 & 0.113 \\
\hline \multirow[t]{2}{*}{ Fat mass (\%) } & $r$ & - & -0.13 \\
\hline & $p$ & 0.070 & 0.002 \\
\hline \multirow[t]{2}{*}{ Fat free mass (kg) } & $r$ & -0.21 & - \\
\hline & $p$ & $<0.001$ & 0.363 \\
\hline \multirow[t]{2}{*}{ Skeletal muscle mass $(\mathrm{kg})$} & $r$ & -0.24 & - \\
\hline & $p$ & $<0.001$ & 0.360 \\
\hline \multirow[t]{2}{*}{ Waist circumference (m) } & $r$ & -0.05 & - \\
\hline & $p$ & 0.048 & 0.067 \\
\hline \multirow[t]{2}{*}{ Weight (kg) } & $r$ & - & - \\
\hline & $p$ & 0.056 & 0.119 \\
\hline \multirow[t]{2}{*}{ Height (m) } & $r$ & - & - \\
\hline & $p$ & 0.818 & 0.413 \\
\hline \multirow[t]{2}{*}{ Visceral adipose tissue (I) } & $r$ & - & - \\
\hline & $p$ & 0.144 & 0.143 \\
\hline \multirow[t]{2}{*}{ Physical activity (MET) } & $r$ & - & -0.84 \\
\hline & $p$ & 0.685 & 0.013 \\
\hline
\end{tabular}

Table 2. Correlation between delta (second minus first measurement) of SOS and BUA and delta of variables. This table illustrates changes in variables and correlation with changes in bone parameters. E.g. for fat mass: earning fat mass in follow-up indicates loosening BUA. $r=P e a r s o n$ correlation coefficient (the correlation index is only given if the p-value is significant). p-value with level of significance $<5 \%$. SOS=speed of sound. BUA=bone ultrasound attenuation. BMI=body mass index. MET=metabolic equivalents per week. 
A multiple regression analysis was performed to investigate the correlation between independent variables and bone parameters (SOS and BUA) (Table 3). Here, too, the deltas of the variables are looked at, i.e. the development of the variables during basic training (delta = value after basic training minus value before basic training). Nearly one-third of the development of SOS can be explained by a model with delta skeletal muscle mass ( $\beta$-coefficient -6.01$)$ and delta weight $(\beta$-coefficient +0.93$)$. Changes in skeletal muscle mass had a negative and weight had a positive influence on delta SOS. About a quarter of the alteration of BUA can be explained by a model including delta fat mass and physical activity, while fat mass ( $\beta$-coefficient -1.74) and physical activity ( $\beta$-coefficient -0.0005$)$ were negatively correlated (Table 3 ). The very low $\beta$-coefficient of physical activity was due to higher absolute values (mean at start=7547.9) than fat mass (mean at start=13.7).

Table 3. Multiple regression results according to bone parameters delta SOS and BUA

\begin{tabular}{|c|c|c|c|c|c|}
\hline Parameter & Independent variables & $\beta$ coefficient & $\begin{array}{l}p \text { value } \\
\text { (variable) }\end{array}$ & $R^{2}($ model $)$ & $\begin{array}{l}p \text { value } \\
\text { (model) }\end{array}$ \\
\hline \multirow[t]{2}{*}{ sos } & $\begin{array}{l}\text { Skeletal muscle mass } \\
(\mathrm{kg})\end{array}$ & -6.01 & $<0.001$ & \multirow[t]{2}{*}{0.32} & \multirow[t]{2}{*}{$<0.001$} \\
\hline & Weight (kg) & 0.93 & 0.086 & & \\
\hline \multirow[t]{2}{*}{ BUA } & Fat mass (\%) & -1.74 & $<0.001$ & \multirow[t]{2}{*}{0.22} & \multirow[t]{2}{*}{$<0.001$} \\
\hline & Physical activity (MET) & -0.0005 & 0.006 & & \\
\hline
\end{tabular}

Table 3: multiple regression analysis of delta (second minus first measurement) SOS and BUA and independent delta variables. After stepwise backward method, skeletal muscle mass and weight remained as predictors for SOS, resp. fat mass and physical activity for BUA. Beta-coefficient describes the extent of SD change in SOS or BUA, if the predictor (independent variable, e.g. skeletal muscle mass) changes by one SD (while the other predictors were held constant). p-value with level of significance < $5 \%$. $R^{2}=$ goodness of fit, describes the proportion of the variation of SOS and BUA, which can be explained by the independent variables (e.g. skeletal muscle mass). SOS=speed of sound. BUA=bone ultrasound attenuation. MET=metabolic equivalents per week.

\section{Discussion}

In this study, we analysed changes in the mechanical and structural properties of bone (SOS and BUA as measured by QUS) and their correlation with anthropometry, body composition, and physical activity in a short-term follow-up setting (18 weeks) during basic military training in a sample of 73 young Swiss men. After basic training, the subjects were heavier, were taller, and had higher fat mass and grip strength. A decrease in physical activity and BUA was observed. Generally, a regression to the mean-like behaviour of all parameters was visible, except for height. Negative correlations were found between development of BUA (delta = value after minus value before basic training) and fat mass as well as physical activity. The same variables were used in the multiple regression analysis. Positive correlations were found between 
development of SOS and grip strength, and negative associations between SOS and skeletal muscle mass as well as waist circumference.

Several studies have investigated the associations of anthropometry and QUS in children, young and elderly adults (particularly women). In children and men, age, weight, height, BMI, and fat-free mass were positively correlated with SOS and BUA, while fat mass and waist circumference were correlated with BUA. Vigorous physical activity correlated positively with SOS and BUA, but dietary factors showed no association (38-40).

In our study, an increase in height during basic training was visible, probably due to the growth. Physical growth can be observed until the age of 24 (41). The general increase in grip strength after basic training is apparently due to the increased stress caused by manual work (f.e. repeated packing, carrying, or putting on and taking off the heavy backpacks).

Unexpectedly after basic training, an increase in weight and fat mass and a decrease in physical activity were observed. No changes in fat-free mass or skeletal muscle mass were observed; thus, it must be assumed that the increase in weight is due to increased fat mass. We have to assume that our participants did less physical activity during the basic training than before, which is probably the main cause of weight gain and increase in fat mass. Furthermore, changes in eating habits (e.g. regular breaks for subsistence) and/or a higher stress level could have additional negative effects on weight and fat mass (42). Worryingly, after the 18-week follow-up, a change in the bone is visible with a significant decrease in the attenuation of the sound, which is synonymous with loss of bone substance $(23,24,32)$. Interestingly, there was a direct correlation between loss of bone and the increase in fat mass, which means that the increase in fat mass in the 18 weeks already harmed the bone status. The negative influence of fat mass on bone metabolism has already been proven several times (43-46). It is known that greater stress on the bone leads to an adaptation and increase in bone mass. However, the stress is only great enough for high-impact sports, walking alone does not lead to an increase in bone, and walking protects against further bone loss in older women $(25,47-52)$. However, it is also known that visceral and subcutaneous adipose tissue negatively affects bone remodelling via inflammatory factors such as the upregulation of the nuclear factor $\mathrm{KB}$ ligand, which leads to a stimulation of the osteoclast activity and thus to bone resorption $(45,46,53-55)$.

The physical activity during the basic training decreased significantly overall, clearly visible in the change of physical activity (delta = value after the basic training minus the value before the start). If the development of physical activity is now looked at in connection with the development of the bone status, a strange result appears at first glance: the recruits with the greatest increase in physical activity tend to show the greatest decrease in ultrasound attenuation and thus the greatest loss of bone substance (Appendix Figure 3A). However, if we consider which recruits show an increase in physical activity during basic training, it becomes apparent that this was only the case with recruits who initially had very little physical activity. Conversely, it can be seen that recruits with a high level of physical activity befor basic training showed the greatest loss of ultrasound attenuation after 18 weeks. These findings suggest that 
this result is subject to a bias. If the initial value of the physical activity is considered, the activity before basic training correlates positively with the ultrasound attenuation and thus with the bone status (Appendix Figure 4).

It is known that air defence recruits have less demand for activities (marches, runs, inactivity per day) than other units in the swiss army (56). Nevertheless, it is worrying that bone loss can already be detected after 18 weeks, probably due to the increase in fat mass and the overall reduced physical activity.

Our study had several strengths and limitations. The strengths include the homogeneous sample of young men, the well-controlled environment, and the amount and type of physical activity and nutrition during basic training. The limitations include the shortcoming of distinguishing between high-and lowimpact activities/sports in the GPAQ. A questionnaire may be answered subjectively; therefore, it has limited reliability. BIA is not the gold standard for measuring body composition. However, due to time constraints within the army setting, we were not able to perform more time-consuming and invasive measurements. In relation, waist circumference could be measured only once because of time constraints. Additionally, by appointing the same experienced researcher, we excluded inter-observer bias; however, an intra-observer bias could not be excluded. Our sample size was limited owing to the setting reasons. As the sample was homogeneous, the internal validity of the study was given, but the external validity was limited. In clinical practice, the implementation of QUS as a screening tool is still limited, mostly due to the lack of standardisation of the QUS measurements and the lack of thresholds for initiating therapy (13). In order to verify the worrying results from our study, a prospective randomized study with a survey of low and high impact activities as well as a detailed survey of eating and nutritional habits during basic training should be carried out. Even more studies including more age groups and both sexes should be performed.

\section{Conclusion}

Overall, we found that the subjects after basic military training were heavier, taller, and thicker, exhibited increased grip strength as well as decreased physical activity and a loss of bone substance. A high level of physical activity before starting the basic training had a protective effect on the bone structure in the follow-up measurement. The high fitness loss of the very active study participants during the basic training suggests a low level of physical and athletic stress on this type of troop, which presumably led to weight gain and, in particular, an increase in fat mass. Terrifyingly, there is a direct statistical association between the increase in fat mass and the decrease in bone substance. As shown in other studies, the force exerted on the bones while walking is not enough to strengthen them. For troop types with a low or medium load pattern, we therefore recommend additional high impact training during basic military training, such as a daily standard jump program with the aim of maintaining or strengthening the bone volume. In order to verify the worrying results of our study, a prospective randomized study with a survey of low and high impact activities as well as a detailed survey of eating and nutrition habits during basic training should be carried out. 


\section{Abbreviations}

$B I A$ bioelectrical impedance analysis

$B M D$ bone mineral density

$B M I$ body mass index

BUA bone ultrasound attenuation

Delta value after basic training minus value at start

DXA dual-energy X-ray absorptiometry

GPAQ Global Physical Activity Questionnaire

$I S C D$ International Society for Clinical Densitometry

MET metabolic equivalents

QUS Quantitative Ultrasound

$S D$ standard deviation

SOS speed of sound

\section{Declarations}

\section{Acknowledgements:}

This paper was part of the Dr. med. thesis project of Michael Straessle. The authors are especially thankful to Andreas Stettbacher (Chief Medical Surgeon), Franz Frey, Martino Ghilardi, and Marco Müller from the Swiss Armed Forces for their tremendous (logistic) support. We also thank the former IEM collaborators Nikola Koepke, Anne Lehner, Claudia Beckmann, and Nakita Frater for helping to collect the data.

\section{Ethics approval and consent to participate:}

Participation in this study was voluntary. The participants signed a detailed informed consent form after oral and written briefings. This study was approved by the Ethics Committee of the Canton of Zurich (No. 2016-01625).

\section{Patient consent for publication:}

Not required. 
Availability of data and materials:

The anonymized dataset used in this paper and the analysis codes can be obtained from the corresponding author.

\section{Funding:}

This work was supported by Mäxi Foundation Zurich (Grantee Frank Rühli)

\section{COI Statement:}

The authors declare that they have no conflicts of interest.

\section{Author contributions:}

KS and MS planned the study, FR provided funding, AF and YJ gave logistic support, KS MS PE JF LÖ LA GA and NB collected data, MS, JG and KS analysed data, MS KS and NB wrote the first draft, all authors commented the manuscript and approved the last version.

\section{References}

1. Wright NC, Saag KG, Dawson-Hughes B, Khosla S, Siris ES. The impact of the new National Bone Health Alliance (NBHA) diagnostic criteria on the prevalence of osteoporosis in the United States: supplementary presentation. Osteoporos Int. 2017;28(11):3283-4.

2. Hernlund E, Svedbom A, Ivergård M, Compston J, Cooper C, Stenmark J, et al. Osteoporosis in the European Union: medical management, epidemiology and economic burden. A report prepared in collaboration with the International Osteoporosis Foundation (IOF) and the European Federation of Pharmaceutical Industry Associations (EFPIA). Arch Osteoporos. 2013;8:136.

3. Srichan W, Thasanasuwan W, Kijboonchoo K, Rojroongwasinkul N, Wimonpeerapattana W, Khouw I, et al. Bone status measured by quantitative ultrasound: a comparison with DXA in Thai children. Eur J Clin Nutr. 2016;70(8):894-7.

4. Bauer DC, Glüer CC, Cauley JA, Vogt TM, Ensrud KE, Genant HK, et al. Broadband ultrasound attenuation predicts fractures strongly and independently of densitometry in older women. A prospective study. Study of Osteoporotic Fractures Research Group. Arch Intern Med. 1997;157(6):629-34.

5. Khaw KT, Reeve J, Luben R, Bingham S, Welch A, Wareham N, et al. Prediction of total and hip fracture risk in men and women by quantitative ultrasound of the calcaneus: EPIC-Norfolk prospective population study. Lancet. 2004;363(9404):197-202.

6. Chan MY, Nguyen ND, Center JR, Eisman JA, Nguyen TV. Quantitative ultrasound and fracture risk prediction in non-osteoporotic men and women as defined by WHO criteria. Osteoporos Int. 2013;24(3):1015-22. 
7. Hollaender R, Hartl F, Krieg MA, Tyndall A, Geuckel C, Buitrago-Tellez C, et al. Prospective evaluation of risk of vertebral fractures using quantitative ultrasound measurements and bone mineral density in a population-based sample of postmenopausal women: results of the Basel Osteoporosis Study. Ann Rheum Dis. 2009;68(3):391-6.

8. Olszynski WP, Brown JP, Adachi JD, Hanley DA, loannidis G, Davison KS, et al. Multisite quantitative ultrasound for the prediction of fractures over 5 years of follow-up: the Canadian Multicentre Osteoporosis Study. J Bone Miner Res. 2013;28(9):2027-34.

9. Esmaeilzadeh S, Cesme F, Oral A, Yaliman A, Sindel D. The utility of dual-energy X-ray absorptiometry, calcaneal quantitative ultrasound, and fracture risk indices (FRAX® and Osteoporosis Risk Assessment Instrument) for the identification of women with distal forearm or hip fractures: A pilot study. Endocr Res. 2016;41(3):248-60.

10. Krieg MA, Cornuz J, Ruffieux C, Sandini L, Büche D, Dambacher MA, et al. Comparison of three bone ultrasounds for the discrimination of subjects with and without osteoporotic fractures among 7562 elderly women. J Bone Miner Res. 2003;18(7):1261-6.

11. Gluer CC. A new quality of bone ultrasound research. IEEE Trans Ultrason Ferroelectr Freq Control. 2008;55(7):1524-8.

12. Marín F, González-Macías J, Díez-Pérez A, Palma S, Delgado-Rodríguez M. Relationship between bone quantitative ultrasound and fractures: a meta-analysis. J Bone Miner Res. 2006;21(7):1126-35.

13. Moayyeri A, Adams JE, Adler RA, Krieg MA, Hans D, Compston J, et al. Quantitative ultrasound of the heel and fracture risk assessment: an updated meta-analysis. Osteoporos Int. 2012;23(1):143-53.

14. Krieg MA, Barkmann R, Gonnelli S, Stewart A, Bauer DC, Del Rio Barquero L, et al. Quantitative ultrasound in the management of osteoporosis: the 2007 ISCD Official Positions. J Clin Densitom. 2008;11(1):163-87.

15. McCloskey EV, Kanis JA, Odén A, Harvey NC, Bauer D, González-Macias J, et al. Predictive ability of heel quantitative ultrasound for incident fractures: an individual-level meta-analysis. Osteoporos Int. 2015;26(7):1979-87.

16. Cesme F, Esmaeilzadeh S, Oral A. Discriminative ability of calcaneal quantitative ultrasound compared with dual-energy X-ray absorptiometry in men with hip or distal forearm fractures. Acta Orthop Traumatol Turc. 2016;50(5):548-53.

17. Force USPST. Screening for osteoporosis: recommendation statement. Am Fam Physician. 2011;83(10):1197-200.

18. Wear KA, Nagaraja S, Dreher ML, Sadoughi S, Zhu S, Keaveny TM. Relationships among ultrasonic and mechanical properties of cancellous bone in human calcaneus in vitro. Bone. 2017;103:93-101.

19. Shepherd JA, Schousboe JT, Broy SB, Engelke K, Leslie WD. Executive Summary of the 2015 ISCD Position Development Conference on Advanced Measures From DXA and QCT: Fracture Prediction Beyond BMD. J Clin Densitom. 2015;18(3):274-86.

20. Thomsen K, Jepsen DB, Matzen L, Hermann AP, Masud T, Ryg J. Is calcaneal quantitative ultrasound useful as a prescreen stratification tool for osteoporosis? Osteoporos Int. 2015;26(5):1459-75. 
21. Hans D, Arlot ME, Schott AM, Roux JP, Kotzki PO, Meunier PJ. Do ultrasound measurements on the os calcis reflect more the bone microarchitecture than the bone mass?: a two-dimensional histomorphometric study. Bone. 1995;16(3):295-300.

22. Guglielmi G, Adams J, Link TM. Quantitative ultrasound in the assessment of skeletal status. Eur Radiol. 2009;19(8):1837-48.

23. Hutmacher DW, Schantz JT, Lam CX, Tan KC, Lim TC. State of the art and future directions of scaffold-based bone engineering from a biomaterials perspective. J Tissue Eng Regen Med. 2007;1(4):245-60.

24. Nicholson PH, Strelitzki R, Cleveland RO, Bouxsein ML. Scattering of ultrasound in cancellous bone: predictions from a theoretical model. J Biomech. 2000;33(4):503-6.

25. van Santen JA, Pereira C, Sanchez-Santos MT, Cooper C, Arden NK. Dominant vs. non-dominant hip comparison in bone mineral density in young sporting athletes. Arch Osteoporos. 2019;14(1):54.

26. Takahata Y. Usefulness of circuit training at home for improving bone mass and muscle mass while losing fat mass in undergraduate female students. Lipids Health Dis. 2018;17(1):104.

27. Välimäki VV, Löyttyniemi E, Välimäki MJ. Quantitative ultrasound variables of the heel in Finnish men aged 18-20 yr: predictors, relationship to bone mineral content, and changes during military service. Osteoporos Int. 2006;17(12):1763-71.

28. Eleftheriou KI, Rawal JS, Kehoe A, James LE, Payne JR, Skipworth JR, et al. The Lichfield bone study: the skeletal response to exercise in healthy young men. J Appl Physiol (1985). 2012;112(4):615-26.

29. Daly RM, Rich PA, Klein R, Bass S. Effects of high-impact exercise on ultrasonic and biochemical indices of skeletal status: A prospective study in young male gymnasts. J Bone Miner Res. 1999;14(7):1222-30.

30. Sager R, Güsewell S, Rühli F, Bender N, Staub K. Multiple measures derived from 3D photonic body scans improve predictions of fat and muscle mass in young Swiss men. PLoS One. 2020;15(6):e0234552.

31. Beckmann C, Aldakak L, Eppenberger P, Rühli F, Staub K, Bender N. Body height and waist circumference of young Swiss men as assessed by 3D laser-based photonic scans and by manual anthropometric measurements. PeerJ. 2019;7:e8095.

32. Liu J, Lan L, Zhou J, Yang Y. Influence of cancellous bone microstructure on ultrasonic attenuation: a theoretical prediction. Biomed Eng Online. 2019;18(1):103.

33. Lee KI, Roh HS, Yoon SW. Acoustic wave propagation in bovine cancellous bone: application of the Modified Biot-Attenborough model. J Acoust Soc Am. 2003;114(4 Pt 1):2284-93.

34. Hodgskinson R, Njeh CF, Whitehead MA, Langton CM. The non-linear relationship between BUA and porosity in cancellous bone. Phys Med Biol. 1996;41(11):2411-20.

35. Bosy-Westphal A, Schautz B, Later W, Kehayias JJ, Gallagher D, Müller MJ. What makes a BIA equation unique? Validity of eight-electrode multifrequency BIA to estimate body composition in a healthy adult population. Eur J Clin Nutr. 2013;67 Suppl 1:S14-21. 
36. Obesity: preventing and managing the global epidemic. Report of a WHO consultation. World Health Organ Tech Rep Ser. 2000;894:i-xii, 1-253.

37. Armstrong T, Bull F. Development of the Global Physical Activity Questionnaire (GPAQ). Journal of Public Health. 2006;14:66-70.

38. Lavado-Garcia JM, Calderon-Garcia JF, Moran JM, Canal-Macias ML, Rodriguez-Dominguez T, Pedrera-Zamorano JD. Bone mass of Spanish school children: impact of anthropometric, dietary and body composition factors. J Bone Miner Metab. 2012;30(2):193-201.

39. Szmodis M, Bosnyák E, Protzner A, Szőts G, Trájer E, Tóth M. Relationship between physical activity, dietary intake and bone parameters in 10-12 years old Hungarian boys and girls. Cent Eur $\mathrm{J}$ Public Health. 2019;27(1):10-6.

40. Babaroutsi E, Magkos F, Manios Y, Sidossis LS. Body mass index, calcium intake, and physical activity affect calcaneal ultrasound in healthy Greek males in an age-dependent and parameterspecific manner. J Bone Miner Metab. 2005;23(2):157-66.

41. Bogin B. Patterns of Human Growth. 2020.

42. Stefanaki C, Pervanidou P, Boschiero D, Chrousos GP. Chronic stress and body composition disorders: implications for health and disease. Hormones (Athens). 2018;17(1):33-43.

43. Zhao LJ, Liu YJ, Liu PY, Hamilton J, Recker RR, Deng HW. Relationship of obesity with osteoporosis. J Clin Endocrinol Metab. 2007;92(5):1640-6.

44. Kim JH, Choi HJ, Kim MJ, Shin CS, Cho NH. Fat mass is negatively associated with bone mineral content in Koreans. Osteoporos Int. 2012;23(7):2009-16.

45. Riggs BL, Khosla S, Melton LJ. Sex steroids and the construction and conservation of the adult skeleton. Endocr Rev. 2002;23(3):279-302.

46. Lee SH, Kim TS, Choi Y, Lorenzo J. Osteoimmunology: cytokines and the skeletal system. BMB Rep. 2008;41(7):495-510.

47. Hind K, Burrows M. Weight-bearing exercise and bone mineral accrual in children and adolescents: a review of controlled trials. Bone. 2007;40(1):14-27.

48. Nikander R, Sievänen H, Heinonen A, Daly RM, Uusi-Rasi K, Kannus P. Targeted exercise against osteoporosis: A systematic review and meta-analysis for optimising bone strength throughout life. BMC Med. 2010;8:47.

49. Heinonen A, Sievänen H, Kannus P, Oja P, Pasanen M, Vuori I. High-impact exercise and bones of growing girls: a 9-month controlled trial. Osteoporos Int. 2000;11(12):1010-7.

50. MacKelvie KJ, McKay HA, Petit MA, Moran 0, Khan KM. Bone mineral response to a 7-month randomized controlled, school-based jumping intervention in 121 prepubertal boys: associations with ethnicity and body mass index. J Bone Miner Res. 2002;17(5):834-44.

51. Fuchs RK, Bauer JJ, Snow CM. Jumping improves hip and lumbar spine bone mass in prepubescent children: a randomized controlled trial. J Bone Miner Res. 2001;16(1):148-56. 
52. Gunter K, Baxter-Jones AD, Mirwald RL, Almstedt H, Fuchs RK, Durski S, et al. Impact exercise increases BMC during growth: an 8-year longitudinal study. J Bone Miner Res. 2008;23(7):986-93.

53. Campos RM, de Piano A, da Silva PL, Carnier J, Sanches PL, Corgosinho FC, et al. The role of pro/anti-inflammatory adipokines on bone metabolism in NAFLD obese adolescents: effects of longterm interdisciplinary therapy. Endocrine. 2012;42(1):146-56.

54. Gilsanz V, Chalfant J, Mo AO, Lee DC, Dorey FJ, Mittelman SD. Reciprocal relations of subcutaneous and visceral fat to bone structure and strength. J Clin Endocrinol Metab. 2009;94(9):3387-93.

55. Russell M, Mendes N, Miller KK, Rosen CJ, Lee H, Klibanski A, et al. Visceral fat is a negative predictor of bone density measures in obese adolescent girls. J Clin Endocrinol Metab. 2010;95(3):1247-55.

56. Wyss T, Scheffler J, Mäder U. Ambulatory physical activity in Swiss Army recruits. Int J Sports Med. 2012;33(9):716-22.

\section{Supplementary Files}

This is a list of supplementary files associated with this preprint. Click to download.

- AppendixTablesandFiguresBMC.docx 